University of South Florida

DIGITAL COMMONS

Digital Commons @ University of

@ UNIVERSITY OF SOUTH FLORIDA

South Florida

Marine Science Faculty Publications

College of Marine Science

2000

\title{
Interannual Mean Sea Level Change and the Earth's Water Mass Budget
}

Don P. Chambers

University of Texas at Austin, donc@usf.edu

Jianli Chen

University of Texas at Austin

R. Steven Nerem

University of Texas at Austin

Byron D. Tapley

University of Texas at Austin

Follow this and additional works at: https://digitalcommons.usf.edu/msc_facpub

Part of the Life Sciences Commons

\section{Scholar Commons Citation}

Chambers, Don P.; Chen, Jianli; Nerem, R. Steven; and Tapley, Byron D., "Interannual Mean Sea Level Change and the Earth's Water Mass Budget" (2000). Marine Science Faculty Publications. 1423.

https://digitalcommons.usf.edu/msc_facpub/1423

This Article is brought to you for free and open access by the College of Marine Science at Digital Commons @ University of South Florida. It has been accepted for inclusion in Marine Science Faculty Publications by an authorized administrator of Digital Commons @ University of South Florida. For more information, please contact digitalcommons@usf.edu. 


\title{
Interannual Mean Sea Level Change and the Earth's Water Mass Budget
}

\author{
Don P. Chambers, Jianli Chen, R. Steven Nerem ${ }^{1}$, and Byron D. Tapley \\ Center for Space Research, University of Texas at Austin
}

\begin{abstract}
The relationship between interannual global mean sea level change and the Earth's water mass budget is examined between 1993 and 1998 by removing the steric (thermal) component from mean sea level computed with TOPEX/Poseidon (T/P) altimetry. The steric component is calculated from subsurface temperatures measured by expendable bathythermographs and interpolated to a global grid by empirical orthogonal function (EOF) reconstruction. Results indicate that from late-1995 to early-1998, the thermal expansion of sea level was significantly higher than the total sea level change measured by $T / P$, suggesting that fresh water mass was lost from the ocean. The size of the maximum water mass lost is equivalent to about $18 \mathrm{~mm}$ of sea level. An error analysis indicates that this value is significant at the $95 \%$ confidence level. Results from numerical models show similar magnitudes of water mass change in the ocean at interannual periods, but at different phases.
\end{abstract}

\section{Introduction}

It is known that the Earth's oceans, atmosphere, and land exchange water mass as part of the hydrological cycle. Previous studies have shown that the mean seasonal cycle of ocean water mass storage can be determined from satellite altimetry corrected with a climatological steric model [Chen et al., 1998; Minster et al., 1999]. In order to study interannual variations, one needs to use a real-time model of the steric correction. We have studied modifying the climatological steric model by adding real-time sea surface temperature measurements to the top levels [Chen et al., 2000], but this model still does not adequately describe interannual steric effects in deeper layers. Instead, we used subsurface temperature measurements made by temperature recorders such as expendable bathythermographs (XBTs) to measure the thermal portion of the steric signal.

Because large portions of the ocean are unsampled by the XBTs the data must be interpolated to a uniform grid for global mean sea level studies. To accomplish this, we have employed a technique known as empirical orthogonal function (EOF) reconstruction [Smith et al., 1996]. The technique is used to interpolate XBT data to a global grid and to compute a monthly global steric correction, which is removed from the mean sea level (MSL) variation determined by TOPEX/Poseidon (T/P) altimetry from January, 1993 to December, 1998 in order to study interannual variations in the

\footnotetext{
${ }^{1}$ Now at Department of Aerospace Engineering Sciences, University of Colorado at Boulder, Boulder, $\mathrm{CO}$, USA.
}

Copyright 2000 by the American Geophysical Union. ocean water mass. Errors are discussed and comparisons are made with output from numerical models.

\section{Data Processing}

$T / P$ altimeter data come from the MGDR-B release for Cycles 10-231 [Benada, 1997]. Sea level anomalies (SLAs) are computed as discussed in Chambers et al. [1997], with the following changes. Data are corrected for a drift that has been detected in the TOPEX Microwave Radiometer [Keihm et al., 1998]. The model removed is a constant drift of $1.2 \mathrm{~mm} \mathrm{yr}^{-1}$ until 1997 then a constant bias of $5.2 \mathrm{~mm}$ after 1997 as recommended [V. Zlotnicki, personal communication, 1999]. Also, an inverted barometer correction which takes into account the time-varying mean pressure over the ocean is applied [Raofi, 1998; Dorendeu and Le Traon, 1999], data are averaged over months from January, 1993 to December, 1998, and the data are gridded into $2.5^{\circ}$ grids before smoothing with the long-wavelength filter.

The XBT data are from the National Oceanographic Data Center [Hamilton, 1994]. Each profile was compared visually and statistically to monthly temperature profiles from the World Ocean Atlas 1994 (WOA94) database [Levitus and Boyer, 1994] and was edited if there were anomalously large temperature increases with depth, or very large scatter in the data.

The steric SLA is computed using a thermal expansion coefficient and the temperature anomaly of XBT temperature relative to WOA94 mean temperatures interpolated to the same level [Chen et al., 1998]. Temperature data are integrated from the deepest XBT level or $1000 \mathrm{~m}$, whichever is smallest. The steric anomalies are then gridded to a $2.5^{\circ} \mathrm{x}$ $2.5^{\circ}$ monthly grid to reduce random error and the effects of single bad measurements. The grids with the most observations are along shipping routes (Figure 1).

The EOF reconstruction technique uses the spatial maps from a principal component analysis as multiple covariance basis functions in place of a single covariance function as in

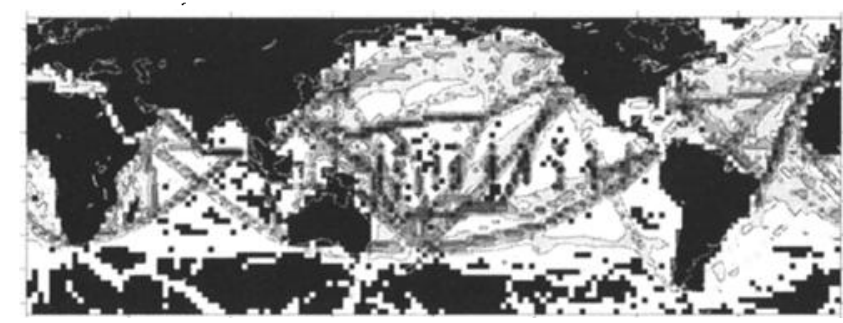

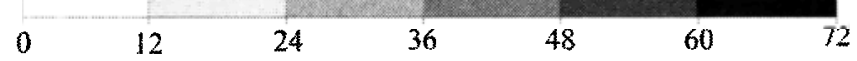

Figure 1. Number of monthly XBT observations per grid. 
optimal interpolation. In essence, the raw data (in this case, the gridded XBT SLAs) are fit to EOF spatial patterns in a least-squares procedure to estimate the temporal coefficients for each mode. A set of coefficients is estimated for each time step (in this case, monthly). Then, a reconstructed grid is computed by multiplying the estimated temporal coefficient and the basis EOF spatial grid, then summing over all the EOF modes. The reconstructed grid will have the same spatial density as the EOF spatial map. Details of the technique can be found in Smith et al. [1996]. An important advantage of EOF reconstruction over standard interpolation techniques is a decreased sensitivity to single point measurements of extreme events, such as mesoscale eddies, which can tend to bias standard interpolations away from the long-wavelength mean.

Because there are no global grids of thermal sea level variations available for interannual periods, we have examined several proxy data to use for EOF maps. These include global SST data [Reynolds and Smith, 1994], heat storage anomalies computed from the Parallel Ocean Climate Model (POCM) Stammer et al., 1996], and SLAs from TOPEX/Poseidon. Global EOF spatial modes are computed for each data set as discussed in Chambers et al. [1999].

In order to evaluate the relative accuracy of the reconstructed grids, they are compared against a set of grids interpolated from the raw XBT grids using the longwavelength filter applied to the T/P data. This filter is based on the XBT data only and an a priori covariance function, so it provides an independent measure of the SLAs measured by the XBT casts. We initially tested the three different sets of EOF spatial modes for the reconstruction, as well as different numbers of modes to see which gave the better relative accuracy. It was found that using 20 modes gave the best results and that the grids reconstructed from the T/P EOFs agreed better with the filtered XBT grids than the other data sets, based on both standard deviation (Figure 2) as well as correlation (not shown). Therefore, the T/P EOF maps are used as basis functions for the reconstruction in this investigation. To remove any seasonal signals in the steric or T/P SLAs, a monthly climatology was computed from 1993 to 1996 and removed from the individual monthly grids.

The mean sea level change ( $\triangle \mathrm{MSL}$ ) is computed from the $\mathrm{T} / \mathrm{P}$ grids and XBT reconstructed grids as a weighted average, where the weight is $\cos$ (latitude). The data have also been smoothed with a 3-month running mean boxcar filter to remove any monthly variations. Figure 3 shows the interannual time-series for $\Delta \mathrm{MSL}_{\mathrm{TP}}$ and $\triangle \mathrm{MSL}_{\mathrm{XBT}}$. The value

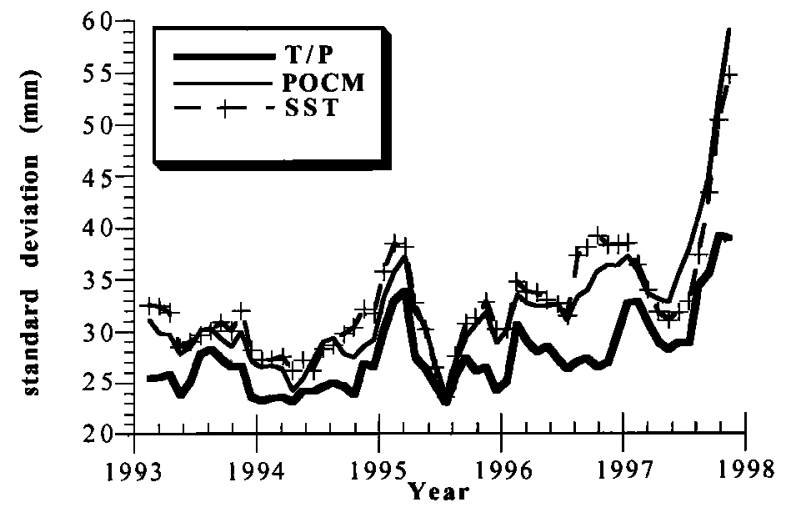

Figure 2. Standard deviation between reconstructed XBT grids and filtered XBT grids for different EOF spatial maps.

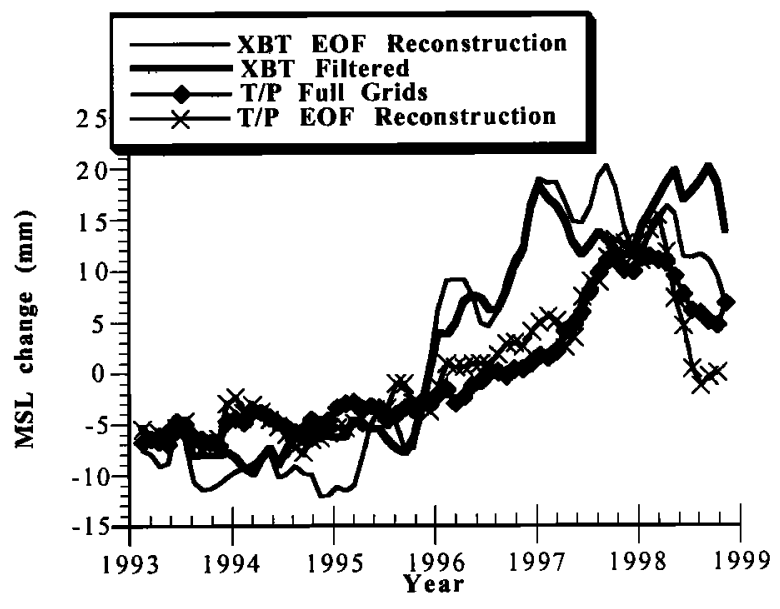

Figure 3. Interannual MSL change from $\mathrm{T} / \mathrm{P}$ and $\mathrm{XBTs}$, utilizing various filtering techniques.

of $\triangle M \mathrm{MSL}_{\mathrm{XBT}}$ for March 1998 exceeded 5-standard deviations (5- $\sigma$ ) because of an abnormally small number of XBT profiles for this month, which degraded the EOF reconstruction. This point was deleted and replaced with the value linearly interpolated from February and April. The steric MSL variation $\left(\triangle M S L_{X B T}\right)$ rose higher than the total sea level variation $\left(\Delta \mathrm{MSL}_{\mathrm{T} / \mathrm{P}}\right)$ in 1997 , and also peaked earlier. This suggests a loss of fresh water mass from the ocean, since to first order the difference between total MSL and steric MSL is interpreted as changes in MSL due to fresh water flux at the surface [Chen et al., 1998].

\section{Error Analysis}

Before discussing the implications of Figure 3, we first discuss the accuracy of the measurements. The seasonal cycle of water mass storage determined from $\mathrm{T} / \mathrm{P}$ and reconstructed XBT data (not shown) agrees well with the results from Chen et al. [1998], which suggests that the reconstruction technique is accurate. To better quantify the accuracy, though, we have examined reconstructing $T / P$ data sampled to the same locations and times as the XBT casts. This was done by finding the closest ascending and descending $\mathrm{T} / \mathrm{P}$ passes to each XBT cast so that there was a pass to the west and east of the XBT location. Then, the T/P 1-sec measurements for each pass were averaged over 10 seconds around the point closest to the XBT cast. This gave two T/P normal points on either side of the XBT cast and at times on either side of the XBT observation. The normal points were then linearly interpolated spatially and temporally to the XBT location. These T/P sampled points were then averaged into monthly $2.5^{\circ}$ grids and the EOF reconstruction was applied. The resulting MSL variation agrees with the "truth" computed from all T/P data within a standard deviation of $2.3 \mathrm{~mm}$ (Figure 3). The agreement degrades slightly in 1998 when there are fewer XBT profiles, but the difference is not significant. Therefore, we estimate the accuracy of the MSL determined from EOF reconstruction to be $5 \mathrm{~mm}$ at the $2-\sigma$ ( $95 \%$ confidence) level.

Overall errors in the T/P and XBT measurements also need to be taken into account. For the T/P data, this is determined by comparing the altimeter data to tide gauge data [Chambers et al., 1998; Mitchum, 1998]. The standard deviation for this comparison is about $3 \mathrm{~mm}$, with a relative drift of less than $0.5 \mathrm{~mm} \mathrm{yr}^{-1}$. Assuming $\sigma$ will decrease slightly for a true 


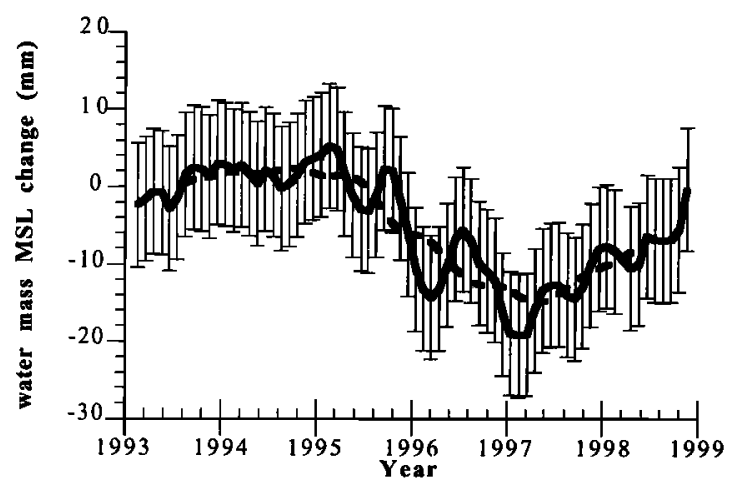

Figure 4. Interannual MSL change due to freshwater mass variations (difference between T/P and XBT curves in Figure 2). The dashed line is a 12-month running mean. Error bars are $2-\sigma$ errors $(95 \%$ confidence level).

global mean, we assume that the $1-\sigma$ value is $2 \mathrm{~mm}$, so that the $2-\sigma$ value is $4 \mathrm{~mm}$. For the XBT data, the error is estimated from the standard deviation between EOF reconstruction and the filtered XBT grids (Figure 3). The 2- $\sigma$ value is $4 \mathrm{~mm}$

Additional errors include neglecting interannual salinity changes in the upper layer and possible temperature changes in the water column beneath the XBT casts. Although salinity effects on local sea level can be relatively large [Maes, 1998; Vossepoel et al., 1999], the effect on MSL will tend to average out. Since there is no direct measure of the global salinity variation, we have estimated it using the precipitation (P) and evaporation (E) rates over the ocean determined from a data assimilating model (see Section 4) and the relationship between P-E and salinity [Gill, 1982]. The resulting MSL signal has a $1-\sigma$ value of less than $0.5 \mathrm{~mm}$, which is similar to the seasonal variance determined from WOA94.

The additional neglected signal is temperature change in the lower layers unsampled by XBT data. In order for the total MSL change in Figure 3 to be lower than the steric MSL change, the water in the lower layer would have had to cool. Since the lower layer can not loose heat to the warm upper layer, it would have had to either loose heat to the solid Earth, or the water would have had to be replaced with colder water from overturning. In the first case, the solid Earth boundaries would have had to cool by more than $10^{\circ} \mathrm{C}$ to cause a sea level drop equivalent to what is observed, which is extremely unlikely.

In the second case, the variability in overturning in the North Atlantic is at most $2 \mathrm{~Sv}\left(2 \times 10^{6} \mathrm{~m}^{3} / \mathrm{s}\right)$ and takes several years to reach that value, based on numerical models [Delworth et al., 1993]. For a conservative approximation, we assume that the maximum change ( $2 \mathrm{~Sv})$ occurs instantaneously in 1995 and remains constant for 700 days. This results in a transfer of order $1 \times 10^{14} \mathrm{~m}^{3}$ of water to the deeper layer. Since an approximately equal volume of deep water will upwell, the volume change will create a MSL change only if the water overturned was at a much different temperature than the water upwelled. For our calculation, we assume the temperature difference is $-5^{\circ} \mathrm{C}$. We also assume that the total volume of cooler water spreads out globally in two years so that the change will effect global mean sea level.

Dividing the overturning volume by the surface area of the ocean (order of $3 \times 10^{14} \mathrm{~m}^{2}$ ) results in a layer approximately $0.3 \mathrm{~m}$ thick and $5^{\circ} \mathrm{C}$ cooler than before, which implies a sea level change of $0.3 \mathrm{~mm}$. Even if we include overturning regions in the Antarctic of the same magnitude, or temperature changes of $15^{\circ} \mathrm{C}$, the sea level change would still be less than $1 \mathrm{~mm}$. Thus it appears that neither overturning nor salinity changes can explain the signal observed. The total error can be estimated from the root sum square of the individual errors, assuming no correlation among the individual errors, and is $8 \mathrm{~mm}$.

\section{Discussion of Results}

Figure 4 shows the interannual time-series of MSL change due to freshwater fluxes (the difference between $\mathrm{MSL}_{\mathrm{T} / \mathrm{P}}$ and $\mathrm{MSL}_{\mathrm{XBT}}$ ). Note the significant decrease in sea level starting in 1995 that indicates a loss of water mass from the ocean. By the time the trend reversed, in 1997, the ocean had lost an amount of water mass equivalent to about $18 \mathrm{~mm}$. Based on the error analysis, this is significant at the $95 \%$ confidence level.

It is difficult to verify that the change in Figure $\mathbf{4}$ is real, as there are no other direct measurements of the water mass cycle. Chen et al. [1998] have shown reasonably good agreement between the $\mathrm{T} / \mathrm{P}$-steric results and a data assimilating model at the seasonal period. We examine whether such an agreement extends to interannual periods. The comparisons are based on the fact that water mass change for the global Earth system is balanced, so changes in the water mass over the ocean are reflected in equal, but opposite changes in the sum of the atmosphere and continental storage. Details can be found in Chen et al. [1998]. Using the NCEPNCAR Data Assimilation System (CDAS-1) [Kalnay et al., 1996], we have examined three cases: 1) continental soil moisture/snow (including West Antarctica) + precipitable water in atmosphere, 2) ocean precipitation (P), evaporation (E), and runoff $(R)$ to compute $(P-E+R)$ over the ocean and hence fresh water flux, and 3) P-E-R over land + precipitable water in atmosphere.

The equivalent MSL changes from the models are plotted in Figure 5 along with the results from this study. Case 1 sees virtually no interannual signal, whereas Cases 2 and 3 see a signal as large as that seen by $\mathrm{T} / \mathrm{P}-\mathrm{XBT}$, although with very different phases. Cases 2 and 3 show a general decrease in MSL attributable to loss of water from the ocean during 1997 , although it is nearly a year out of phase with the T/P-XBT

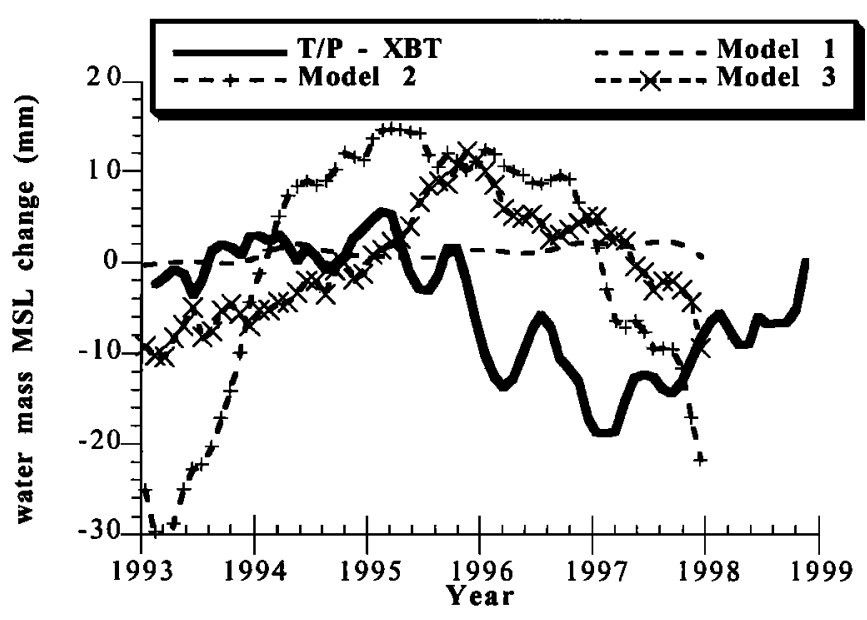

Figure 5. MSL change due to freshwater mass variations from T/P and XBT measurements and 3 different models discussed in the text. 
results. However, the magnitudes are similar. The T/P-XBT and Case 3 results agree within the error bounds until 1996, then diverge, but Case 2 indicates a very large change in 1993-1994 that is not seen in the data or the other models. These results suggest that the current models are inadequate for resolving interannual variations in the hydrological cycle.

Recent studies [e.g., Nerem et al., 1999] have shown a high correlation between global mean SST (MSST) and MSL during 1993 to 1998 . From this one might conclude that steric sea level and total sea level are not significantly different if it is assumed that a constant scaling converts MSST to MSL. However, this ignores the fact that subsurface temperature changes are different than SST changes and that the thermocline depth can change by hundreds of meters, especially in the tropics during El Niño events. These factors suggest a time-varying scaling factor. We also point out that when EOF modes from SST data are used in the reconstruction, the reconstructed steric grids compare significantly worse with interpolated grids than when $T / P$ EOF grids are used (Figure 2), which indicates a fundamental difference between SST variability and steric variability.

\section{Conclusions}

The results of this study suggest that the ocean lost an equivalent of $18 \mathrm{~mm}$ of MSL between 1995 and 1997 due to fresh water loss. The large thermal expansion at the same time compensated for this so that MSL rose during the $1997 \mathrm{El}$ Niño [Nerem et al., 1999]. The timing of the initiation of the water loss cycle preceded the $1997 \mathrm{El} \mathrm{Niño} \mathrm{by} \mathrm{nearly} \mathrm{a} \mathrm{year.}$ Its connection with the dynamics of El Niño, if any, is unknown but is under investigation.

Although results from models do not agree well with the observations for the interannual variation, two of them do predict a similar magnitude of change, which suggests that the change observed by T/P and the XBT data is reasonable. The best validation of this technique will not be possible for several years, however. By then, the Gravity and Climate Experiment (GRACE) should be monitoring changes in the gravity field associated with water mass variations in the Earth system components. Estimates suggest that GRACE should be able to measure local water mass as small as a few mm of water [Wahr et al., 1998]. If this technique can be verified using Jason-1 altimetry and XBT data during the GRACE mission, we can then use the T/P-XBT results to produce a decadal time-series of mean water mass storage in the Earth's oceans.

Acknowledgments. The authors would like to thank Jennifer Cregar for helping to preprocess and visually inspect the XBT casts. We would also like to thank Richard Coleman, Gary Lagerloef, and Gary Mitchum for informative discussions on this subject. T/P data are from the Jet Propulsion Laboratory Physical Oceanography Data Archive Center. The XBT data are from the National Oceanographic Data Center. This research was supported by the Earth Observing System Interdisciplinary Science Program at NASA under contract NAG5-6309.

\section{References}

Benada, R., TOPEX/POSEIDON merged GDR generation B user's handbook, JPL Rep. D-11007, Jet. Propul. Lab.,Pasadena, Calif., 1997.
Chambers, D. P., B. D. Tapley, and R. H. Stewart, Long-period ocean heat storage rates and basin-scale heat fluxes from TOPEX, J. Geophys. Res. 102, 10,525-10,533, 1997.

Chambers, D. P., B. D. Tapley, and R. H. Stewart, Anomalous warming in the Indian Ocean coincident with El Niño, $J$. Geophys. Res., 104, 3035-3047, 1999

Chambers, D. P., J. C. Ries, C. K. Shum, and B. D. Tapley, On the use of tide gauges to determine altimeter drift, J. Geophys. Res., 103, 12885-12890, 1998.

Chen, J. L., C. R. Wilson, D. P. Chambers, R. S. Nerem, and B. D. Tapley, Seasonal global water mass balance and mean sea level variations, Geophys. Res. Ltrs., 25, 3555-3558, 1998.

Chen, J. L., C. K. Shum, C. R. Wilson, D. P. Chambers, and B. D. Tapley, The steric sea level change and TOPEX/POSEIDON observations, J. Geophys. Res., in press, 1999.

Delworth, T., S. Manabe, and R. J. Stouffer, Interdecadal variations of the thermohaline circulation in a coupled ocean-atmosphere model, J. Climate, 6, 1993-2001, 1993.

Dorandeu, J., and P. Y. Le Traon, Effects of global mean atmospheric pressure variations on mean sea level changes from TOPEX/POSEIDON, J. of Atmos. Oceanic. Tech., 16, 1279-1283, 1999.

Gill, A. E., Atmosphere-Ocean Dynamics, 662 pp., Academic, San Diego, CA, 1982.

Hamilton, D., GTSPP builds an ocean temperature-salinity database, Earth System Monitor, June, 1994.

Kalnay, E., et al., The NCEP/NCAR 40-year reanalysis project, Bull. Amer. Meteor. Soc., 77, 437-471, 1996.

Keihm, S. V. Zlotnicki, and C. Ruf, TOPEX Microwave Radiometer Performance Evaluation, IEEE Trans. Geos. Rem. Sens., 38, 1379-1389, 2000.

Levitus, S., and T. P. Boyer, World Ocean Atlas 1994, vol. 2 , Temperature, NOAA Atlas NESDIS 2, 99 pp., Natl. Oceanıc and Atmos. Admin., Silver Spring, Md., 1994.

Maes, C., Estimating the influence of salinity on sea level anomaly in the ocean, Geophys. Res. Ltrs., 25, 3551-3554, 1998.

Minster, J. F., A. Cazenave, and P. Rogel, Annual cycle in mean sea level from Topex-Poseidon and ERS-1: Inference on the global hydrological cycle, Global and Planetary Change, 20, 57-60, 1999.

Mitchum, G., Monitoring the stability of satellite altimeters with tide gauges, J. of Atmos. Oceanic. Tech., 15, 721-730, 1998.

Nerem, R. S., D. P. Chambers, E. Leuliette, G. T. Mitchum, and B. S. Giese, Variations In Global Mean Sea Level During The 1997-98 ENSO Event, Geophys. Res. Lirs., 26, 3005-3008, 1999.

Raofi, B., Ocean's response to atmospheric pressure loading: The inverted barometer approximation for altimetry measurements, CSR-98-1, Center for Space Research, Austin, TX, 1998.

Reynolds, R. W., and T. M. Smith, Improved global sea surface temperature analysis using optimum interpolation, J. Clim., 7, 929-948, 1994.

Smith T. M., R. W. Reynolds, R. E. Livezey, and D. C. Stokes, Reconstruction of historical sea surface temperatures using empirical orthogonal functions, J. Climate, 9, 1403-1420, 1996.

Stammer, D., R. Tokmakian, A. Semtner, and C. Wunsch, How well does a $1 / 4^{\circ}$ global circulation model simulate large-scale oceanic observations?, J. Geophys. Res., 101, 25,779-25,812, 1996.

Vossepoel, F. C., R. W. Reynolds, and L. Miller, Use of sea level observations to estimate salinity variability in the tropical Pacific, J. of Atmos. Oceanic. Tech., 16, 1401-1415, 1999.

Wahr, J., M. Molenaar, and F. Bryan, Time-variability of the Earth's gravity field: Hydrological and oceanic effects and their possible detection using GRACE, J. Geophys. Res., 103, 32,205-30,229, 1998.

D. P. Chambers, J. L. Chen, R. S. Nerem, and B. D. Tapley, Center for Space Research, University of Texas at Austin, Austin, TX, USA.

(e-mail: chambers@csr.utexas.edu)

(Received March 2. 2000; accepted August 4, 2000.) 